Article

\title{
Triacylglycerols and Fatty Acid Compositions of Cucumber, Tomato, Pumpkin, and Carrot Seed Oils by Ultra-Performance Convergence Chromatography Combined with Quadrupole Time-of-Flight Mass Spectrometry
}

\author{
Yanfang $\mathrm{Li}^{1,+}{ }^{\dagger}$, Fanghao Yuan ${ }^{1,+}$, Yanbei $\mathrm{Wu}^{2}$, Yaqiong Zhang ${ }^{1}\left(\mathbb{D}\right.$, Boyan Gao ${ }^{1, *(\mathbb{C})}$ \\ and Liangli $\mathrm{Yu}^{3}$ (D) \\ 1 Institute of Food and Nutraceutical Science, School of Agriculture and Biology, Shanghai Jiao Tong \\ University, Shanghai 200240, China; zoe_li@sjtu.edu.cn (Y.L.); yuanfanghao@sjtu.edu.cn (F.Y.); \\ yqzhang2006@sjtu.edu.cn (Y.Z.) \\ 2 Beijing Advanced Innovation Center for Food Nutrition and Human Health, Beijing Technology \& Business \\ University (BTBU), Beijing 100048, China; yanbeiwu@btbu.edu.cn \\ 3 Department of Nutrition and Food Science, University of Maryland, College Park, MD 20742, USA; \\ lyu5@umd.edu \\ * Correspondence: gaoboyan@sjtu.edu.cn; Tel.: +86-021-34204538 \\ + Authors made equal contributions to the manuscript.
}

Received: 2 July 2020; Accepted: 20 July 2020; Published: 22 July 2020

\begin{abstract}
The triacylglycerol (TAG) compositions of cucumber, tomato, pumpkin, and carrot seed oils were analyzed using ultra-performance convergence chromatography $\left(\mathrm{UPC}^{2}\right)$ combined with quadrupole time-of-flight mass spectrometry (Q-TOF MS). A total of 36, 42, 39, and 27 different TAGs were characterized based on their Q-TOF MS accurate molecular weight and MS$^{2}$ fragment ion profiles in the cucumber, tomato, pumpkin, and carrot seed oils, respectively. Generally, different vegetable seed oils had different TAGs compositions. Among the identified fatty acids, linoleic acid was the most abundant fatty acid in cucumber, tomato, and pumpkin seed oils and the second most abundant in carrot seed oil with relative concentrations of 54.48, 48.69, 45.10, and $15.92 \mathrm{~g} / 100 \mathrm{~g}$ total fatty acids, respectively. Oleic acid has the highest concentration in carrot seed oil and the second highest in cucumber, tomato, and pumpkin seed oils, with relative concentrations of 78.97, 18.57, 27.16 , and $33.39 \mathrm{~g} / 100 \mathrm{~g}$ total fatty acids, respectively. The chemical compositions of TAGs and fatty acids could promote understanding about the chemical profiles of certain vegetable seed oils, thus improving the potential ability to select appropriate oils with specific functions and a high nutritional value and then develop functional foods in the future.
\end{abstract}

Keywords: triacylglycerol compositions; vegetable seed oils; ultra-performance convergence chromatography ( $\mathrm{UPC}^{2}$ ); quadrupole time-of-flight mass spectrometry (Q-TOF MS); fatty acid composition

\section{Introduction}

Cucumber (Cucumis sativus), tomato (Solanum lycopersicum), pumpkin (Curcubita pepo), and carrot (Daucus carota) are widely consumed vegetables around the world. After industrial manufacturing, these vegetables could be processed into canned food, juice, smoothies, sauce, etc., thus they became more acceptable due to their convenience, health, nutrition, and safety $[1,2]$. Following industrial processing, significant amounts of vegetable seeds end up as waste, even though they have been found 
to contain significant amounts of healthy components such as lipids, protein, dietary fiber, and other bioactive compounds [3-7]. Among the nutrients in these seeds, lipid is one of the most important components, which contains more than $95 \%$ triacylglycerols (TAGs) $[5,8]$. Recently, increasing evidence has demonstrated that not only the fatty acid compositions, but also their binding positions in TAGs play very important roles in the functionality and nutrition values of seed oils [9-12]. For example, binding positions of fatty acids to TAG altered their oxidative stability, calcium absorption, and lipid metabolism [11]. Previous researches have investigated the fatty acid compositions of these seed oils, however very little research has been conducted on the exact chemical structures and compositions of TAGs in these seed oils, especially on the binding positions of fatty acids in TAGs [5,13-18]. Thus, in order to clarify the potential availability of developing nutritional components from these wasted seeds, it is worthwhile investigating the TAGs positional profiles and compositions of cucumber, tomato, pumpkin, and carrot seed oils.

Recently, the development of supercritical $\mathrm{CO}_{2}$ ultra-performance convergence chromatography $\left(\mathrm{UPC}^{2}\right)$ provided an advanced and efficient method for the separation of low polarity compounds and was conducive to reduce the usage of organic solvents $[19,20]$. Besides, the high-resolution quadrupole time-of-flight mass spectrometry (Q-TOF MS) system was able to provide accurate molecular mass weight and fragment ion information of TAGs and therefore played an important role in identifying the binding position of fatty acid side chains. The combination of UPC ${ }^{2}$ and Q-TOF MS technology has been used to examine TAGs compositions of cow milk fat [20], sunflower, corn, soybean oils [21], and olive oils [22] due to the excellent resolution and separation ability.

In this study, TAG composition and their binding positions, as well as the composition of free fatty acids in cucumber, tomato, pumpkin, and carrot seed oils were evaluated using UPC ${ }^{2}$-Q-TOF-MS and GC-MS, respectively. The relative concentrations of the identified TAGs and free fatty acids were also semi-quantified based on the area normalization method. Results from this study could improve the utilization of these seed oils as functional ingredients, along with increased profits of vegetable manufacturers and reduced environmental hazards.

\section{Materials and Methods}

\subsection{Materials and Regents}

Cucumber, tomato, pumpkin, and carrot seed oil samples were gifted from the Botanic Innovations (Spooner, WI, USA) and stored at $-20{ }^{\circ} \mathrm{C}$ before analyses. Acetonitrile, methanol, isopropanol, and ammonium formate were of LC-MS grade and purchased from Sigma-Aldrich (St. Louis, MO, USA). Fatty acid methyl ester (FAME) mix standard (contented 37 FAMEs) was purchased from NU-CHEK Inc. (Elysian, MN). Food-grade $\mathrm{CO}_{2}$ (purity > 99.99\%) was supplied by Zhenxin Gas Co. Ltd. (Shanghai, China). Ultrapure water was purified by a Millipore Milli-Q 10 ultrapure water system (Billerica, MS, USA) with TOC value below $5 \mathrm{ppb}$ and resistivity of $18.2 \mathrm{~m} \Omega\left(25^{\circ} \mathrm{C}\right)$. All the other chemical reagents of analytical grade were purchased from Sigma-Aldrich (St. Louis, MA, USA) and utilized without further purification.

\subsection{Sample Preparations}

The cucumber, tomato, pumpkin, and carrot seed oil samples were prepared based on previous lab protocol [21]. Briefly, $10 \mu \mathrm{L}$ of each seed oil sample and $990 \mu \mathrm{L}$ of acetonitrile/methanol/isopropanol $(10: 9: 1, v / v / v)$ were vortex-mixed for $20 \mathrm{~s}$ and centrifuged at $2000 \mathrm{rpm}$ for $5 \mathrm{~min}$ at an ambient temperature. After the supernatant was removed, the residue was vortex-dissolved thoroughly with $990 \mu \mathrm{L}$ of isopropanol. The final mixture of the residue and isopropanol was used for UPC ${ }^{2}$-Q-TOF MS analysis and each sample was prepared in triplicates. 


\subsection{UPC ${ }^{2}$ System Condition}

The conditions of UPC ${ }^{2}$ were set according to our previous manuscript [22]. A Waters Acquity ultra-performance convergence chromatography (UPC ${ }^{2}$ ) system (Milford, MA, USA) equipped with a binary pump, an oven, an auto-sampler, a back-pressure regulator, and an Acquity UPC ${ }^{2}$ BEH HSS $C_{18}$ column $(150 \mathrm{~mm} \times 3.0 \mathrm{~mm}$ i.d.; $1.7 \mu \mathrm{m})$ was utilized for the separation of TAGs. The back pressure was $1800 \mathrm{psi}$ and column oven temperature was $30^{\circ} \mathrm{C}$. The mobile phase A was pure supercritical fluid $\mathrm{CO}_{2}$ and the mobile phase $\mathrm{B}$ was methanol. The flow rate was $1.6 \mathrm{~mL} / \mathrm{min}$ and the injection volume was $2.0 \mu \mathrm{L}$. The elution gradient started at $99 \%$ A, decreased linearly to $98.2 \%$ A over $5 \mathrm{~min}$, decreased linearly to $98 \%$ A over the next $7 \mathrm{~min}$, decreased linearly to $97 \%$ over the next $3 \mathrm{~min}$, decreased linearly to $70 \%$ over the next minute, was held at $70 \%$ A for $3 \mathrm{~min}$, and back to $99 \%$ A to re-equilibrate the column. Methanol with $0.1 \%$ ammonium formate as a compensated solvent was pumped at a flow rate of $0.3 \mathrm{~mL} / \mathrm{min}$ by a Waters 1525 pump.

\subsection{Quadrupole Time-of-Flight (Q-TOF) MS Conditions}

A Waters Xevo-G2 Q-TOF MS system was utilized to characterize the chemical structures of TAGs in cucumber, tomato, pumpkin, and carrot seed oils. The electrospray ionization (ESI) in positive mode was used in a mass range from 100 to $1200 \mathrm{Da}$ at a capillary voltage of $3.0 \mathrm{kV}$ and a cone voltage of $50.0 \mathrm{~V}$. The source offset was $80.0 \mathrm{~V}$. Leucine enkephalin was used as the lock mass (m/z 556.2771 in ESI ${ }^{+}$). The source temperature was $120^{\circ} \mathrm{C}$ and the desolvation temperature was $500^{\circ} \mathrm{C}$. The desolvation gas (nitrogen) was set at a flow of $800.0 \mathrm{~L} / \mathrm{h}$ and the collision gas (argon) was set at $150.0 \mathrm{~L} / \mathrm{h}$.

Data were collected using Masslynx 4.1 software (Milford, MA, USA) in MS ${ }^{\mathrm{E}}$ mode. The MS acquisition method consisted of a low collision energy mode $\left(\mathrm{MS}^{1}\right)$ and a high collision energy mode $\left(\mathrm{MS}^{2}\right)$. In the MS ${ }^{1}$ mode, the collision energy was $6 \mathrm{eV}$ and parent ions were obtained. The information of fragment ions was collected in the MS ${ }^{2}$ mode and the collision energy was $35 \mathrm{eV}$. The scan time was $0.2 / \mathrm{s}$.

\subsection{Free Fatty Acid Composition Analysis}

Free fatty acid compositions of cucumber, tomato, pumpkin, and carrot seed oils were determined by previous lab protocol [23]. Briefly, $20 \mathrm{mg}$ of each oil sample was vortex mixed thoroughly with $0.4 \mathrm{~mL}$ of methylbenzene and $0.4 \mathrm{~mL}$ of $\mathrm{KOH}-\mathrm{MeOH}(0.5 \mathrm{~mol} / \mathrm{L})$. The mixture was sealed and heated at $60{ }^{\circ} \mathrm{C}$ for $10 \mathrm{~min}$. After cooling the reaction mixture to an ambient temperature, $2 \mathrm{~mL}$ of boron trifluoride-MeOH (14\%) was added and the mixture, which was sealed with a lid, was heated at $60^{\circ} \mathrm{C}$ for $5 \mathrm{~min}$. Before being vortexed, $2 \mathrm{~mL}$ of isooctane and $3 \mathrm{~mL}$ of ultrapure water were added. The supernatant was injected for GC analysis. Fatty acid compositions were determined using Agilent 7890A gas chromatograph equipped with FID detector and DB-23 silica capillary column (60 m length $\times 0.25 \mathrm{~mm}$ with a $0.25 \mu \mathrm{m}$ film thickness) using helium as the carrier gas. The injection volume was $1 \mu \mathrm{L}$. The oven temperature was initially at $100^{\circ} \mathrm{C}$ and increased to $184{ }^{\circ} \mathrm{C}$ by $10.5^{\circ} \mathrm{C} / \mathrm{min}$. After holding at $184^{\circ} \mathrm{C}$ for $3 \mathrm{~min}$, it was increased again to $240^{\circ} \mathrm{C}$ at a rate of $6^{\circ} \mathrm{C} / \mathrm{min}$. Fatty acid methyl esters were identified by the retention time compared with those of the standard FAMEs. Relative concentrations of identified fatty acids were quantified based on the area normalization method, which is calculated using each identified individual peak area divided by the total area of all peaks identified in the extracts. Each sample was analyzed in triplicate.

\subsection{Statistical Analysis}

The relative concentrations of TAGs and fatty acids were reported as the mean \pm standard deviation (SD) based on the peak area normalization method. The relative concentrations of each TAG and fatty acid were analyzed with one-way ANOVA and Tukey's post hoc test using SPSS 18.0 (Chicago, IL, USA), and $p<0.05$ was considered a significant difference. 


\section{Results and Discussion}

\subsection{Identification of TAGs}

A total of 36, 42, 39, and 27 different TAGs were tentatively identified in the cucumber, tomato, pumpkin, and carrot seed oils, respectively (Table 1). Representative base peak intensity (BPI) chromatograms of cucumber, tomato, pumpkin, and carrot seed oils obtained by UPC ${ }^{2}-\mathrm{Q}-\mathrm{TOF}-\mathrm{MS}$ are presented in Figure 1. The TAG compositions in the seed oils were determined using the accurate mass data of quasi-molecular ions of $\left[\mathrm{M}+\mathrm{NH}_{4}\right]^{+}$and $\mathrm{MS}^{2}$ fragmentation ions of $[\mathrm{M}+\mathrm{H}]^{+}$information $[21,22]$. There are three typical types of TAGs: TAG that contain 3 same fatty acid side chains; or 3 different fatty acid side chains; or 2 same and 1 different fatty acid side chain with the different one at sn- 2 or sn-1/sn-3 position. Three mass spectrums were presented to explain the identification of these three typical types of TAGs (Figures 2-4).

Peak 25 was selected as an example to clarify the identification of TAG containing 3 same fatty acids. Peak 25 had the quasi-molecular ion of $\left[\mathrm{M}+\mathrm{NH}_{4}\right]^{+}$at $\mathrm{m} / \mathrm{z} 902.8221$ (Figure 2a), referred to as the chemical formula of $\mathrm{C}_{57} \mathrm{H}_{104} \mathrm{O}_{6}$. The $\mathrm{MS}^{2}$ daughter ion of diacyl fragment in peak 25 was $\mathrm{m} / \mathrm{z} 603.5405$ $\left([\mathrm{M}-\mathrm{RCOO}+\mathrm{H}]^{+}\right)$, representing the only fragment of $[\mathrm{O}-\mathrm{O}]^{+}$(Figure $2 \mathrm{~b}$ ). The lost ion fragment had a molecular mass of 299.2773, suggesting that the lost fatty acid was oleic acid. Therefore, peak 25 was identified to be O-O-O.

Peak 23 was selected as an example to explain the identification of TAG containing 2 different fatty acids. Peak 23 had the quasi-molecular ion of $\left[\mathrm{M}+\mathrm{NH}_{4}\right]^{+}$at $\mathrm{m} / \mathrm{z} 900.8048$ (Figure 3a), referred to as $\mathrm{C}_{57} \mathrm{H}_{102} \mathrm{O}_{6}$. The $\mathrm{MS}^{2}$ daughter ion of diacyl fragments in peak 23 were $\mathrm{m} / \mathrm{z} 603.5345$ and 601.5236 $\left([\mathrm{M}-\mathrm{RCOO}+\mathrm{H}]^{+}\right)($Figure $3 \mathrm{~b})$, representing the fragments of $[\mathrm{O}-\mathrm{O}]^{+}$and $[\mathrm{O}-\mathrm{L}]^{+}$with relative natural abundances of $41 \%$ and $100 \%$, respectively. It has been previously proved that fatty acids on sn-2 position binding to TAGs have greater bond energy and are harder to be eliminated in $\mathrm{MS}^{2}$ collision energy mode than those on sn- 1 and sn-3 positions $[20-22,24,25]$. The ratio of $[\mathrm{O}-\mathrm{L}]^{+}$and $[\mathrm{O}-\mathrm{O}]^{+}$was over 2:1, suggesting that peak 23 could be tentatively identified as O-L-O.

Peak 27 was selected as an example for clarifying the identification of a TAG containing 3 different fatty acids. Peak 27 had the quasi-molecular ion of $\left[\mathrm{M}+\mathrm{NH}_{4}\right]^{+}$at $\mathrm{m} / \mathrm{z} 902.8200$ (Figure 4a), referred to as $\mathrm{C}_{57} \mathrm{H}_{104} \mathrm{O}_{6}$. The $\mathrm{MS}^{2}$ daughter ion of diacyl fragments in peak 27 were $\mathrm{m} / \mathrm{z} 601.5211,603.5370$, and $605.5519\left([\mathrm{M}-\mathrm{RCOO}+\mathrm{H}]^{+}\right)($Figure $4 \mathrm{~b})$, representing the fragments of $[\mathrm{O}-\mathrm{L}]^{+},[\mathrm{L}-\mathrm{S}]^{+}$, and $[\mathrm{O}-\mathrm{S}]^{+}$, with relative natural abundances of $90.25 \%, 96.33 \%$, and $81.91 \%$, respectively. In consideration of the MS rules regarding the fatty acid position and their bond energies mentioned above, linoleic acid was assigned to sn-2 position since the relative abundance of $[\mathrm{O}-\mathrm{S}]^{+}$was the lowest in nature. Then, peak 27 was identified as S-L-O.

A total of 36 TAGs were tentatively identified in cucumber seed oil, with SLO as the most abundant TAG, followed by LLO and LLL (Table 1). Further, 23 of the identified TAGs, namely PLPo, LnPoL, PLnLn, PoLL, PLLn, LnLnLn, SLS, SOS, LLG, LLA, OLG, LOA, OOA, SLA, OSA, LLB, OLB, LSB, LLT, OLT, LLLi, LOLi, and LLH, were reported in cucumber seed oil for the first time. By extrapolating the ratios of increments for fatty acids to the HPLC retention of component TAGs, Deineka and others found OLLn, OOO, and PPO in cucumber seed oil 20- and 30-days after fruit setting, which were not detected in the present study [26]. Different TAG compositions in cucumber seed oil may be due to different identification techniques as well as different ripening and growing conditions of the cucumber samples. 
Table 1. Identification and relative concentration of triacylglycerols in cucumber, pumpkin, carrot, and tomato seed oils.

\begin{tabular}{|c|c|c|c|c|c|c|c|c|c|}
\hline \multirow{2}{*}{$\begin{array}{r}\text { Peak } \\
\text { No. }\end{array}$} & \multirow{2}{*}{$\begin{array}{c}\text { Rt } \\
(\mathrm{min})\end{array}$} & \multirow{2}{*}{$\begin{array}{c}\text { Observed } \\
\left(\left[\mathrm{M}+\mathrm{NH}_{4}\right]^{+}\right)\end{array}$} & \multirow{2}{*}{$\begin{array}{l}\text { Chemical } \\
\text { Formula }\end{array}$} & \multirow{2}{*}{$\begin{array}{l}\text { Possible } \\
\text { Structure }\end{array}$} & \multirow{2}{*}{ UB } & \multicolumn{4}{|c|}{ TAGs Composition (g/100 g TAGs) } \\
\hline & & & & & & Cucumber & Tomato & Pumpkin & Carrot \\
\hline 1 & 5.17 & 844.7394 & $\mathrm{C}_{53} \mathrm{H}_{94} \mathrm{O}_{6}$ & M-L-L & 4 & $1.49 b \pm 0.12$ & $1.56 b \pm 0.03$ & $0.85 a \pm 0.01$ & nd \\
\hline 3 & 5.52 & 846.7550 & $\mathrm{C}_{53} \mathrm{H}_{96} \mathrm{O}_{6}$ & P-L-Po & 3 & $0.93 a \pm 0.06$ & $1.79 b \pm 0.04$ & nd & nd \\
\hline 4 & 5.76 & 848.7707 & $\mathrm{C}_{53} \mathrm{H}_{98} \mathrm{O}_{6}$ & P-Po-O & 2 & nd & nd & nd & $0.60 \mathrm{a} \pm 0.01$ \\
\hline 5 & 6.05 & 848.7707 & $\mathrm{C}_{53} \mathrm{H}_{98} \mathrm{O}_{6}$ & P-L-P & 2 & $2.82 \mathrm{~d} \pm 0.01$ & $2.11 b \pm 0.08$ & $2.31 c \pm 0.06$ & $0.34 \mathrm{a} \pm 0.00$ \\
\hline 8 & 5.44 & 870.7551 & $\mathrm{C}_{55} \mathrm{H}_{96} \mathrm{O}_{6}$ & Po-L-L & 5 & $1.83 c \pm 0.16$ & $2.08 \mathrm{~d} \pm 0.09$ & $0.96 b \pm 0.11$ & $0.59 a \pm 0.02$ \\
\hline 9 & 5.76 & 870.7554 & $\mathrm{C}_{55} \mathrm{H}_{96} \mathrm{O}_{6}$ & P-L-Ln & 5 & $1.11 b \pm 0.02$ & $1.50 \mathrm{c} \pm 0.04$ & $0.37 a \pm 0.02$ & nd \\
\hline 10 & 6.01 & 872.7707 & $\mathrm{C}_{55} \mathrm{H}_{98} \mathrm{O}_{6}$ & P-L-L & 4 & $7.27 \mathrm{~d} \pm 0.17$ & $4.95 b \pm 0.25$ & $5.62 \mathrm{c} \pm 0.20$ & $2.54 \mathrm{a} \pm 0.05$ \\
\hline 11 & 5.70 & 872.7715 & $\mathrm{C}_{55} \mathrm{H}_{98} \mathrm{O}_{6}$ & Po-L-O & 4 & nd & nd & $0.67 a \pm 0.08$ & $3.38 b \pm 0.11$ \\
\hline 12 & 6.33 & 874.7864 & $\mathrm{C}_{55} \mathrm{H}_{100} \mathrm{O}_{6}$ & P-O-L & 3 & $5.30 \mathrm{a} \pm 0.18$ & $5.30 \mathrm{a} \pm 0.17$ & $5.48 \mathrm{a} \pm 0.07$ & $5.83 b \pm 0.03$ \\
\hline 17 & 5.55 & 892.7394 & $\mathrm{C}_{57} \mathrm{H}_{94} \mathrm{O}_{6}$ & L-Ln-Ln & 8 & nd & $0.55 b \pm 0.03$ & nd & $0.17 \mathrm{a} \pm 0.01$ \\
\hline 18 & 5.70 & 894.7551 & $\mathrm{C}_{57} \mathrm{H}_{96} \mathrm{O}_{6}$ & L-L-Ln & 7 & $2.07 b \pm 0.08$ & $3.97 \mathrm{c} \pm 0.17$ & $0.63 a \pm 0.06$ & $0.52 \mathrm{a} \pm 0.02$ \\
\hline 19 & 5.87 & 896.7707 & $\mathrm{C}_{57} \mathrm{H}_{98} \mathrm{O}_{6}$ & L-L-L & 6 & $10.17 \mathrm{~d} \pm 0.09$ & $7.52 \mathrm{c} \pm 0.11$ & $7.26 b \pm 0.10$ & $3.38 a \pm 0.09$ \\
\hline 20 & 6.19 & 898.7864 & $\mathrm{C}_{57} \mathrm{H}_{100} \mathrm{O}_{6}$ & O-L-L & 5 & $11.16 \mathrm{~d} \pm 0.10$ & $7.05 a \pm 0.29$ & $7.97 b \pm 0.25$ & $10.27 c \pm 0.06$ \\
\hline 21 & 6.58 & 900.8021 & $\mathrm{C}_{57} \mathrm{H}_{102} \mathrm{O}_{6}$ & $\mathrm{~L}-\mathrm{O}-\mathrm{O}$ & 4 & $6.83 b \pm 0.28$ & $5.62 \mathrm{a} \pm 0.06$ & $9.18 \mathrm{c} \pm 0.34$ & nd \\
\hline 22 & 6.90 & 900.8020 & $\mathrm{C}_{57} \mathrm{H}_{102} \mathrm{O}_{6}$ & L-S-L & 4 & $8.93 c \pm 0.09$ & $4.93 a \pm 0.11$ & $5.47 \mathrm{~b} \pm 0.11$ & nd \\
\hline 23 & 6.47 & 900.8019 & $\mathrm{C}_{57} \mathrm{H}_{102} \mathrm{O}_{6}$ & O-L-O & 4 & nd & nd & nd & $15.33 a \pm 0.13$ \\
\hline 24 & 7.29 & 902.8178 & $\mathrm{C}_{57} \mathrm{H}_{104} \mathrm{O}_{6}$ & O-S-L & 3 & nd & nd & $9.37 b \pm 0.18$ & $6.14 a \pm 0.10$ \\
\hline 25 & 6.94 & 902.8177 & $\mathrm{C}_{57} \mathrm{H}_{104} \mathrm{O}_{6}$ & $\mathrm{O}-\mathrm{O}-\mathrm{O}$ & 3 & nd & $2.70 \mathrm{a} \pm 0.08$ & $4.94 b \pm 0.19$ & $22.53 c \pm 0.24$ \\
\hline 26 & 7.32 & 902.8181 & $\mathrm{C}_{57} \mathrm{H}_{104} \mathrm{O}_{6}$ & S-O-L & 3 & nd & $7.46 a \pm 0.27$ & nd & nd \\
\hline 27 & 7.36 & 902.8177 & $\mathrm{C}_{57} \mathrm{H}_{104} \mathrm{O}_{6}$ & S-L-O & 3 & $11.55 a \pm 0.25$ & nd & nd & nd \\
\hline 36 & 8.53 & 930.8490 & $\mathrm{C}_{59} \mathrm{H}_{108} \mathrm{O}_{6}$ & L-O-A & 3 & $1.66 \mathrm{a} \pm 0.11$ & $2.64 b \pm 0.10$ & nd & nd \\
\hline 37 & 7.96 & 930.8481 & $\mathrm{C}_{59} \mathrm{H}_{108} \mathrm{O}_{6}$ & $\mathrm{O}-\mathrm{O}-\mathrm{G}$ & 3 & nd & nd & nd & $4.87 \mathrm{a} \pm 0.08$ \\
\hline 38 & 8.53 & 930.8499 & $\mathrm{C}_{59} \mathrm{H}_{108} \mathrm{O}_{6}$ & O-L-A & 3 & nd & nd & $3.33 b \pm 0.18$ & $0.73 a \pm 0.01$ \\
\hline 39 & 9.63 & 932.8646 & $\mathrm{C}_{59} \mathrm{H}_{110} \mathrm{O}_{6}$ & L-S-A & 2 & nd & $1.54 \mathrm{a} \pm 0.07$ & $1.58 \mathrm{a} \pm 0.15$ & nd \\
\hline 40 & 9.06 & 932.8649 & $\mathrm{C}_{59} \mathrm{H}_{110} \mathrm{O}_{6}$ & O-O-A & 2 & $0.22 \mathrm{a} \pm 0.01$ & $1.06 b \pm 0.02$ & $1.39 c \pm 0.09$ & $1.29 c \pm 0.03$ \\
\hline 41 & 9.63 & 932.8651 & $\mathrm{C}_{59} \mathrm{H}_{110} \mathrm{O}_{6}$ & S-L-A & 2 & $1.98 \mathrm{a} \pm 0.11$ & nd & nd & nd \\
\hline 42 & 10.30 & 934.8803 & $\mathrm{C}_{59} \mathrm{H}_{112} \mathrm{O}_{6}$ & O-S-A & 1 & $0.21 \mathrm{a} \pm 0.01$ & $0.74 \mathrm{c} \pm 0.04$ & $0.53 b \pm 0.05$ & nd \\
\hline 43 & 9.06 & 954.8490 & $\mathrm{C}_{61} \mathrm{H}_{108} \mathrm{O}_{6}$ & Ln-L-B & 5 & nd & $0.17 a \pm 0.01$ & nd & $0.16 a \pm 0.00$ \\
\hline 44 & 9.37 & 956.8646 & $\mathrm{C}_{61} \mathrm{H}_{110} \mathrm{O}_{6}$ & L-L-B & 4 & $0.43 a \pm 0.01$ & $0.81 b \pm 0.05$ & $0.96 b \pm 0.12$ & nd \\
\hline 45 & 8.77 & 956.8662 & $\mathrm{C}_{61} \mathrm{H}_{110} \mathrm{O}_{6}$ & O-L-E & 4 & nd & nd & nd & $0.26 a \pm 0.01$ \\
\hline 46 & 9.94 & 958.8803 & $\mathrm{C}_{61} \mathrm{H}_{112} \mathrm{O}_{6}$ & O-L-B & 3 & $0.28 \mathrm{a} \pm 0.01$ & nd & $1.08 b \pm 0.09$ & $0.22 \mathrm{a} \pm 0.01$ \\
\hline 47 & 9.27 & 958.8807 & $\mathrm{C}_{61} \mathrm{H}_{112} \mathrm{O}_{6}$ & O-E-O & 3 & nd & nd & nd & $0.40 \mathrm{a} \pm 0.01$ \\
\hline 48 & 10.01 & 958.8802 & $\mathrm{C}_{61} \mathrm{H}_{112} \mathrm{O}_{6}$ & S-L-E & 3 & nd & $0.56 a \pm 0.03$ & nd & nd \\
\hline 49 & 10.65 & 960.8959 & $\mathrm{C}_{61} \mathrm{H}_{114} \mathrm{O}_{6}$ & $\mathrm{O}-\mathrm{O}-\mathrm{B}$ & 2 & nd & $0.19 a \pm 0.03$ & $0.41 b \pm 0.04$ & $0.47 b \pm 0.01$ \\
\hline 50 & 11.25 & 960.8964 & $\mathrm{C}_{61} \mathrm{H}_{114} \mathrm{O}_{6}$ & L-S-B & 2 & $0.62 \mathrm{a} \pm 0.04$ & $1.32 b \pm 0.06$ & $0.58 \mathrm{a} \pm 0.05$ & nd \\
\hline 51 & 10.16 & 970.8803 & $\mathrm{C}_{62} \mathrm{H}_{112} \mathrm{O}_{6}$ & L-L-T & 4 & $0.12 \mathrm{a} \pm 0.02$ & $0.17 \mathrm{~b} \pm 0.01$ & $0.15 a b \pm 0.02$ & nd \\
\hline 52 & 10.83 & 972.8959 & $\mathrm{C}_{62} \mathrm{H}_{114} \mathrm{O}_{6}$ & O-L-T & 3 & $0.05 a \pm 0.00$ & $0.10 \mathrm{~b} \pm 0.00$ & $0.13 c \pm 0.01$ & nd \\
\hline 53 & 10.58 & 982.8803 & $\mathrm{C}_{63} \mathrm{H}_{112} \mathrm{O}_{6}$ & Ln-L-Li & 5 & nd & $0.15 a \pm 0.01$ & nd & nd \\
\hline 54 & 11.01 & 984.8976 & $\mathrm{C}_{63} \mathrm{H}_{114} \mathrm{O}_{6}$ & L-L-Li & 4 & $0.53 a \pm 0.03$ & $1.51 b \pm 0.06$ & $0.56 a \pm 0.05$ & nd \\
\hline 55 & 11.72 & 986.9116 & $\mathrm{C}_{63} \mathrm{H}_{116} \mathrm{O}_{6}$ & L-O-Li & 3 & $0.28 b \pm 0.02$ & $0.93 \mathrm{~d} \pm 0.01$ & $0.49 c \pm 0.02$ & $0.14 a \pm 0.00$ \\
\hline 56 & 12.42 & 1010.9116 & $\mathrm{C}_{65} \mathrm{H}_{116} \mathrm{O}_{6}$ & Ln-L-H & 5 & nd & $0.11 \mathrm{a} \pm 0.01$ & nd & nd \\
\hline 57 & 12.91 & 1012.9272 & $\mathrm{C}_{65} \mathrm{H}_{118} \mathrm{O}_{6}$ & L-L-H & 4 & $0.22 b \pm 0.01$ & $0.75 c \pm 0.04$ & $0.08 a \pm 0.00$ & nd \\
\hline
\end{tabular}

TAGs stands for triacylglycerols; RT represents retention time; UB represents the number of unsaturated double bonds; nd represents not detectable; P: palmitic acid, Po: palmitoleic acid, M: myristic acid, S: stearic acid, O: oleic acid, L: linoleic acid, Ln: linolenic acid, G: gondoic acid, A: arachidic acid, B: behenic acid, Li: lignoceric acid, E: Erucic acid, T: Tricosanoic acid, H: Hexacosanoic acid. X-X-Y, X-Y-X, X-X-X, and X-Y-Z represent structures of triacylglycerols, for example, S-P-O stands for the structure of 1/3-stearoyl-2-palmitoyl-1/3-oleoylglycerol. The relative concentration of each triacylglycerol is reported as grams of triacylglycerols/100 $\mathrm{g}$ of oil samples. Cucumber, tomato, pumpkin, and carrot seed oils were analyzed in triplicate and results reported as mean \pm standard deviation (SD). Different letters represent significant differences within a column $(p<0.05)$. 
C-2

(a)

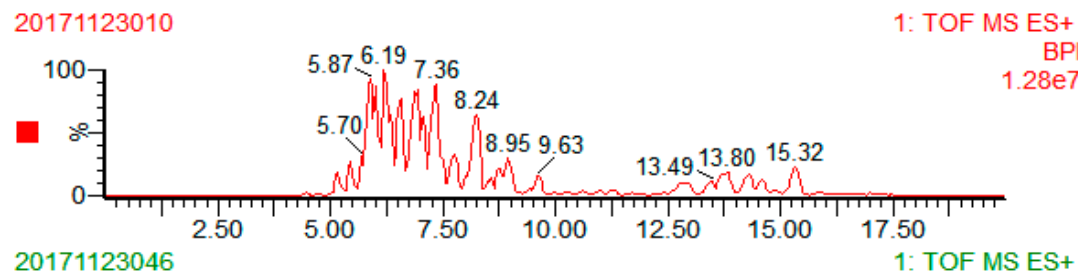

(b)

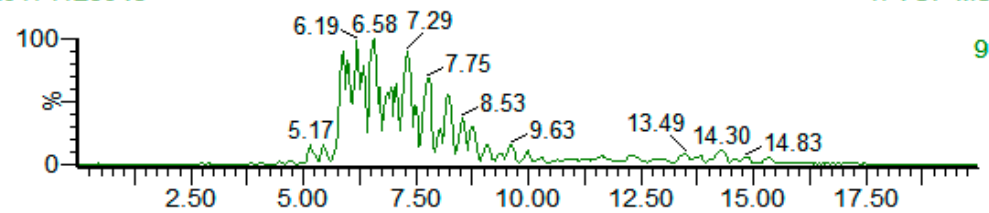

(c)
20171123050
1: TOF MS ES+

$10076.47 \quad 6.94$

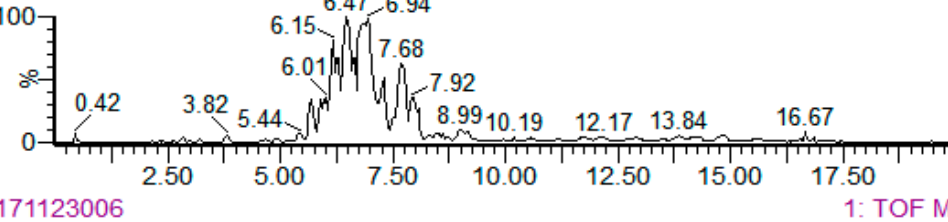

(d)

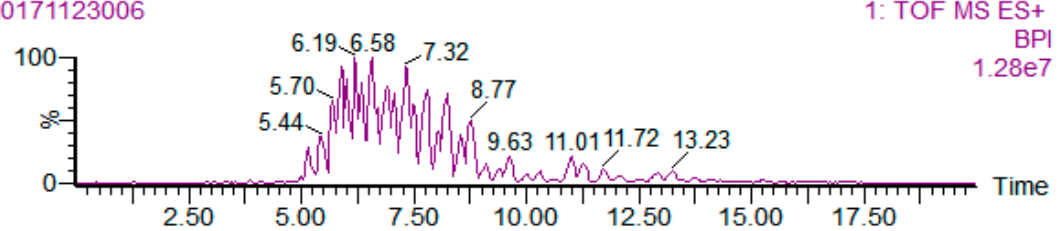

Figure 1. UPC ${ }^{2} / \mathrm{Q}-\mathrm{TOF}$ MS BPI chromatograms of (a) cucumber, (b) pumpkin, (c) carrot, and (d) tomato seed oil samples. BPI stands for base peak integration.

R-1

20171123048196 (6.935) Cm (192:197)

(a)

(a)
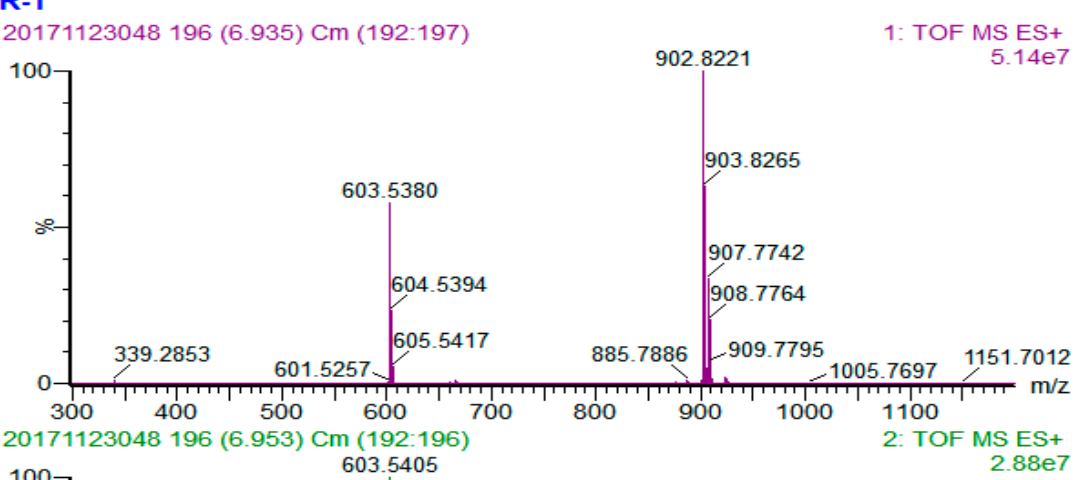

(b)

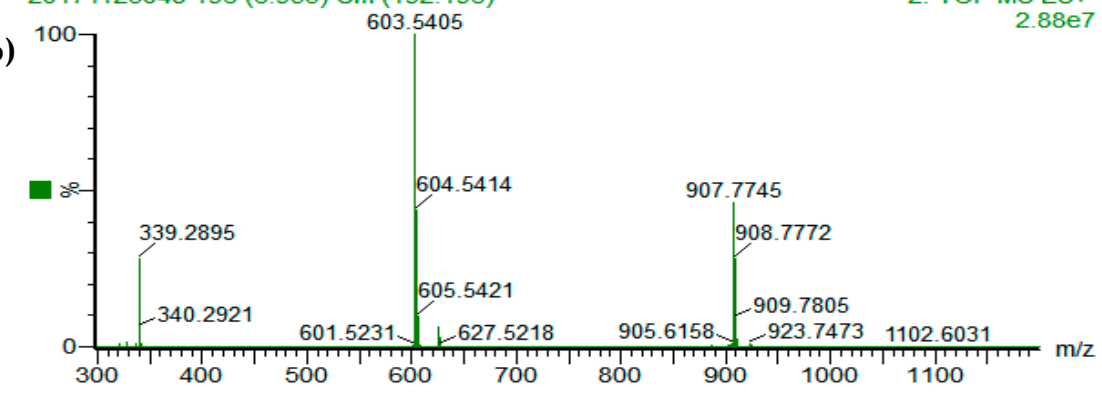

Figure 2. MS spectra of O-O-O. (a) $\mathrm{MS}^{1}$ spectrum and (b) $\mathrm{MS}^{2}$ spectrum. 
R-1

20171123048183 (6.473) Cm (181:185)

(a) 100
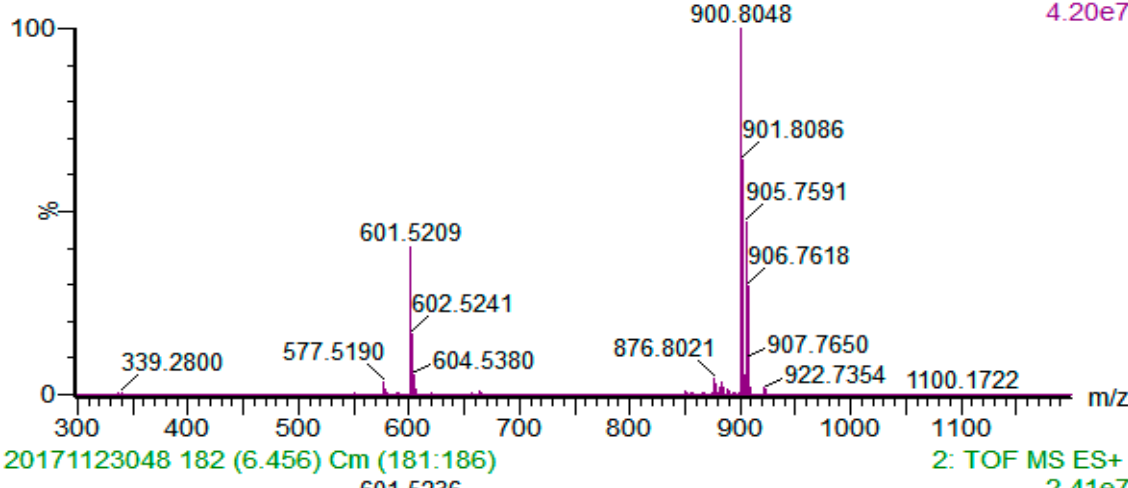

(b)

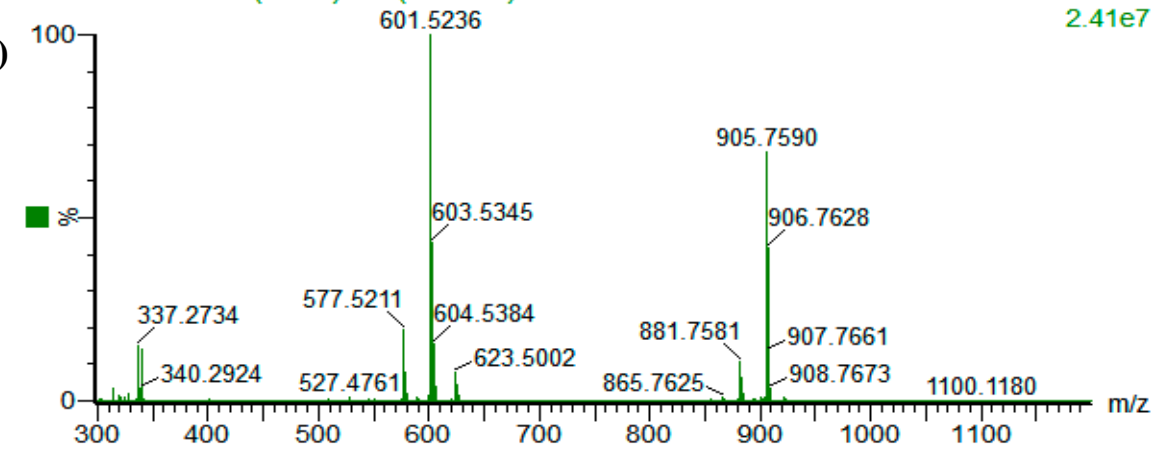

Figure 3. MS spectra of O-L-O. (a) MS ${ }^{1}$ spectrum and (b) $\mathrm{MS}^{2}$ spectrum.

\section{C-2}

20171123010207 (7.324) Cm (204:209)

(a) 100

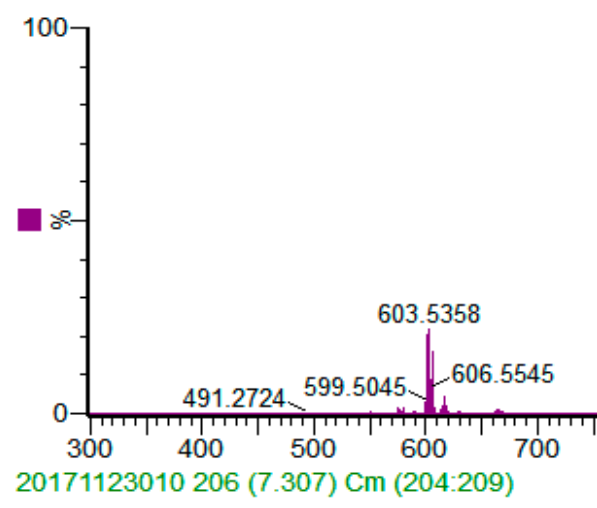

(b)

(204.209)

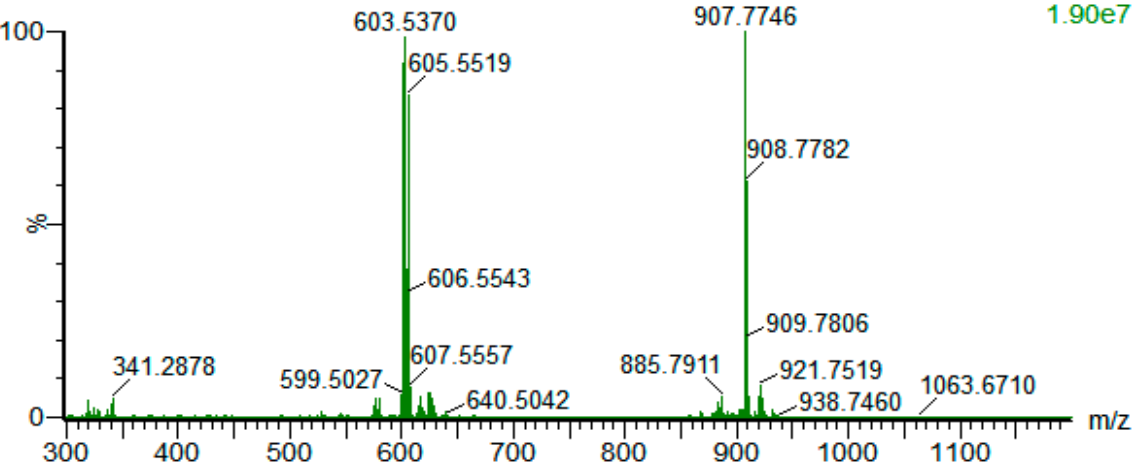

Figure 4. MS spectra of S-L-O. (a) $\mathrm{MS}^{1}$ spectrum and (b) $\mathrm{MS}^{2}$ spectrum. 
A total of 42 TAGs were detected and identified in tomato seed oil, with LLL, SOL, and OLL as the three major TAGs (Table 1). Among all the identified TAGs, 33 of them including SOO, SLS, PLS, LLLn, SOS, LLA, LOA, PLP, PoLL, PLPo, MLL, LSA, LLLi, PLLn, LSB, OOA, LOLi, LLB, LLH, OSA, LnPoL, SLE, LLnLn, LLG, OLG, LnLA, PLnLn, OOB, LLT, LnLB, LnLLi, LnLH, and OLT were reported in tomato seed oil for the first time. Silva and others calculated the theoretical compositions of 5 triacylglycerols in tomato seed oil according to a computer program developed based on the fatty acid profile by Antoniosi Filho, Mendes, and Lanças [27], which were all directly detected and identified in the present study [7]. Compared with the identification strategy of TAGs based on the fatty acid compositions, UPC ${ }^{2}$-Q-TOF MS technology not only directly showed higher accuracy and feasibility, but also provided the actual structure of TAGs, which is not limited by the detection of fatty acid composition.

A total of 39 TAGs were identified in pumpkin seed oil and OSL, LOO, and OLL were the three major TAGs, with a relative concentration of 9.37, 9.18, and 7.97 g/100 g TAGs, respectively (Table 1). Among all the 39 TAGs, 22 of them, namely OLA, LLA, LSA, OOA, OLB, PoOO, PoLL, LLB, MLL, PoLO, OLG, LSB, LLLi, OSA, LOLi, LLG, OOB, PLnLn, LnPoL, LLT, OLT, and LLH were reported in pumpkin seed oil for the first time. On the other hand, LnLnLn, LLnLn, OLnLn, OLLn, OOLn, SLLn, POLn, POP, POS, and PPS have been reported in previous results [26,28-32] but not detected in this study. These differences might due to the different varieties of the seed samples and the different identification techniques that were used.

Similarly, a total of 27 TAGs were detected in carrot seed oil, with OOO, OLO, and OLL having the highest concentrations of 22.53, 15.33, and $10.27 \mathrm{~g} / 100 \mathrm{~g}$ TAGs, respectively (Table 1). In agreement with a previous study, Giuffrè found that $\mathrm{OOO}$ was the highest TAG in all detected virgin and extra virgin olive oil and constituted 30-50\% of the total TAGs by detecting the TAG content of 10 different cultivars grown in South West Calabria [33]. Considering that olive oil is a vegetable oil with many recognized biological properties [34], carrot seed oil may have similar bioactivates but warrants additional research to reveal its specific health effects. There are 17 TAGs, including OSL, OOG, PoOO, OLG, OLA, PPoO, PoLL, LLLn, MOL, OOB, OEO, PLP, OLE, OLB, LLnLn, LnLB, and LOLi, that were reported in carrot seed oil for the first time. Thao and others found 10 TAGs in carrot seed oil using LC-Q-TOF MS and seven of them, including OOO, OLO, OSO, POO, LLL, PoLO, and OOA, were also detected in the present study, whereas OLLn, LAA, and LnLnLn were not observed [35].

\subsection{Fatty Acid Compositions}

Four major fatty acids, including palmitic acid (C16:0), stearic acid (C18:0), oleic acid (C18:1), and linoleic acid (C18:2) were identified and their relative concentrations for each seed oil sample were investigated and are listed in Table 2. Linoleic acid was the most abundant fatty acid in cucumber, tomato, and pumpkin seed oils and the second abundant in carrot seed oil, with relative concentrations of $54.48,48.69,45.10$, and $15.92 \mathrm{~g} / 100 \mathrm{~g}$ total fatty acids, respectively (Table 2 ). The results were consistent with previous studies that linoleic acid had the highest content of $68.1 \%, 54.7 \%$, and $56.4 \%$ in cucumber, tomato, and pumpkin seed oils, respectively $[5,26]$. Conjugated linoleic acid has been associated with several vital biological functions such as antitumor, anti-obesity, antidiabetic, anti-inflammatory, and cardioprotective activities [36-38], suggesting that the consumption of cucumber, tomato, and pumpkin seed oils in daily life might be good for human health, but more research is needed to verify its accuracy. In addition, oleic acid has the highest concentration in carrot seed oil and was the second abundant in cucumber, tomato, and pumpkin seed oils, with relative concentrations of 78.97, $18.57,27.16$, and $33.39 \mathrm{~g} / 100 \mathrm{~g}$ total fatty acids, respectively (Table 2 ). The content of oleic acid was in agreement with previous reports, contributing about $68.1-81.2 \%$ in carrot seed oil $[13,35]$. As we know, oleic acid is not only the most important monounsaturated fatty acid in the diet, but also the predominate constituent of plasma free fatty acids with many bioactivities such as anti-tumor, anti-inflammatory, and cardioprotective functions [34,39-41]. For an extra virgin olive oil, oleic acid has to be in the $55-83 \%$ range of the total fatty acids [42,43], which is widely considered as a healthy 
oil. With many properties such as anti-oxidant, anti-inflammatory, and cardiovascular protective effects [34]. Consumption of carrot seed oil might have similar health effects as olive oil, but more investigation is needed in the future. Palmitic acid was the third abundant fatty acid in cucumber, tomato, pumpkin, and carrot seed oils, with concentrations of 14.98, 16.81, 14.21, and 5.07 g/100 g total fatty acids, respectively (Table 2). The content of stearic acid in cucumber, tomato, pumpkin, and carrot seed oils were $11.97,7.34,7.29$, and $1.04 \mathrm{~g} / 100 \mathrm{~g}$ total fatty acids, respectively (Table 2). Some minor content fatty acids such as linolenic, behenic, arachidic, lignoceric, eicosenoic, palmitoleic, and myristic acids were detected in previous studies in these seed oils, however they were not detected in this study $[5,13,16,35]$. This might be due to the fact that the content of these fatty acids (FAs) was under a detectable level in the present study, which may be caused by different cultivars or different harvest times of these seed samples [44].

Table 2. Identification and relative concentration of fatty acid compositions in cucumber, pumpkin, carrot, and tomato seed oil samples.

\begin{tabular}{cccccc}
\hline \multirow{2}{*}{ Fatty Acid } & C:D & \multicolumn{4}{c}{ Fatty Acid Composition (g/100 g total FAs) } \\
\cline { 3 - 6 } & & Cucumber & Tomato & Pumpkin & Carrot \\
\hline Palmitic acid & $16: 0$ & $14.98 \mathrm{~b} \pm 0.35$ & $16.81 \mathrm{~b} \pm 0.43$ & $14.21 \mathrm{~b} \pm 0.05$ & $5.07 \mathrm{a} \pm 0.08$ \\
Stearic acid & $18: 0$ & $11.97 \mathrm{c} \pm 0.70$ & $7.34 \mathrm{~b} \pm 1.16$ & $7.29 \mathrm{~b} \pm 0.32$ & $1.04 \mathrm{a} \pm 0.03$ \\
Oleic acid & $18: 1$ & $18.57 \mathrm{a} \pm 0.17$ & $27.16 \mathrm{c} \pm 0.52$ & $33.39 \mathrm{~d} \pm 0.10$ & $78.97 \mathrm{e} \pm 0.29$ \\
Linoleic acid & $18: 2$ & $54.48 \mathrm{e} \pm 0.85$ & $48.69 \mathrm{~d} \pm 0.25$ & $45.10 \mathrm{c} \pm 0.04$ & $15.92 \mathrm{~b} \pm 0.18$ \\
\hline
\end{tabular}

FAs stands for fatty acids; C:D represents carbon number:double bounds number. The relative concentration of each fatty acid is reported as grams of fatty acids/ $100 \mathrm{~g}$ of total fatty acids. Cucumber, pumpkin, carrot, and tomato seed oils were analyzed in triplicate and results are reported as mean \pm standard deviation (SD). Different letters represent significant differences within a column $(p<0.05)$.

In the comparison of fatty acid compositions determined using gas chromatography directly and calculated from TAGs compositions (Table 3), 7 of 16 relative deviations (RDs) were less than $8 \%$, which means that most of the TAGs compositions identified in this study were consistent with their fatty acid composition results. But there was still one result with an abnormal RD value of stearic acid in carrot seed oil greater than $70 \%$, which might be due to its low relative concentration of $1.04 \mathrm{~g} / 100 \mathrm{~g}$ total fatty acids. The relative deviations of oleic acid and linoleic acid indicated good consistency between the determined value and calculated value in cucumber $(-2.01 \%, 2.23 \%)$, pumpkin $(-0.24 \%, 6.22 \%)$, and tomato $(3.74 \%, 2.94 \%)$ seed oils. These results showed that the determined value was close to the calculated value in general.

Table 3. Comparison of relative concentration of fatty acid compositions determined by GC and calculated by triacylglycerols compositions in cucumber, pumpkin, carrot, and tomato seed oil samples.

\begin{tabular}{|c|c|c|c|c|c|c|c|c|c|c|c|c|}
\hline \multirow{3}{*}{ Fatty Acid } & \multicolumn{12}{|c|}{ Fatty Acid Composition (g/100 g total FAs) } \\
\hline & \multicolumn{3}{|c|}{ Cucumber } & \multicolumn{3}{|c|}{ Tomato } & \multicolumn{3}{|c|}{ Pumpkin } & \multicolumn{3}{|c|}{ Carrot } \\
\hline & MV & $\mathrm{CV}$ & RD & MV & $\mathrm{CV}$ & RD & MV & $\mathrm{CV}$ & RD & MV & $\mathrm{CV}$ & RD \\
\hline Palmitic acid & 14.98 & 9.95 & $50.55 \%$ & 16.81 & 10.01 & $67.93 \%$ & 14.21 & 8.8 & $61.48 \%$ & 5.07 & 5.33 & $-4.88 \%$ \\
\hline Stearic acid & 11.97 & 17.81 & $-32.79 \%$ & 7.34 & 16.43 & $-55.33 \%$ & 7.29 & 15.27 & $-52.26 \%$ & 1.04 & 4.98 & $-79.12 \%$ \\
\hline Oleic acid & 18.57 & 18.95 & $-2.01 \%$ & 27.16 & 26.18 & $3.74 \%$ & 33.39 & 33.47 & $-0.24 \%$ & 78.97 & 63.26 & $24.83 \%$ \\
\hline Linoleic acid & 54.48 & 53.29 & $2.23 \%$ & 48.69 & 47.3 & $2.94 \%$ & 45.1 & 42.46 & $6.22 \%$ & 15.92 & 26.43 & $-39.77 \%$ \\
\hline
\end{tabular}

$\mathrm{MV}$, mean value of fatty acid compositions determined by GC; CV, calculated value of fatty acid compositions calculated from triacylglycerols compositions reported in Table $1 ; \mathrm{RD}$, relative deviation.

\section{Conclusions}

In summary, a total of 36, 42, 39, and 27 different TAGs were identified in the cucumber, tomato, pumpkin, and carrot seed oils, respectively. A total of 23, 33, 22, and 17 TAGs detected in cucumber, tomato, pumpkin, and carrot seed oils were reported for the first time. Generally, different vegetable seed oils contained different TAGs compositions. SLO, LLL, OSL, and OOO were the most abundant 
TAGs in cucumber, tomato, pumpkin, and carrot seed oil, with relative concentrations of $11.55,7.52$, 9.37, and $22.53 \mathrm{~g} / 100 \mathrm{~g}$ TAG, respectively. Among the identified fatty acids, linoleic acid concentration was the highest in cucumber, tomato, and pumpkin seed oils and the second highest in carrot seed oil, with relative concentrations of $54.48,48.69,45.10$, and $15.92 \mathrm{~g} / 100 \mathrm{~g}$ total fatty acids, respectively. Oleic acid was the most abundant in carrot seed oil and the second most abundant in cucumber, tomato, and pumpkin seed oils, with relative concentrations of 78.97, 18.57, 27.16, and $33.39 \mathrm{~g} / 100 \mathrm{~g}$ total fatty acids, respectively. UPC ${ }^{2}$-Q-TOF MS technology was utilized to analyze the TAGs in four vegetable seed oils and showed higher accuracy and feasibility than the identification strategy based on the fatty acid composition. These results could provide a reference for selecting appropriate oils with specific functions and high nutritional values to develop functional foods in the future.

Author Contributions: Conceptualization, Y.Z. and Y.W.; funding acquisition, B.G.; investigation, Y.L. and F.Y.; supervision, L.Y.; writing-original draft, Y.L. and F.Y.; writing-review \& editing, Y.L. and B.G. All authors have read and agreed to the published version of the manuscript.

Funding: This research was funded by the National Key Research and Development Program of China (Grant No. 2018YFC1602400) and SJTU startup fund for young talent (Grant No. 18X100040051).

Acknowledgments: We sincerely appreciate all the samples gifted from Botanic Innovations (Spooner, WI, USA).

Conflicts of Interest: The authors declare that they do not have any conflict of interest.

\section{References}

1. Ragaert, P.; Verbeke, W.; Devlieghere, F.; Debevere, J. Consumer perception and choice of minimally processed vegetables and packaged fruits. Food Qual. Prefer. 2004, 15, 259-270. [CrossRef]

2. Liu, R.H. Health-promoting components of fruits and vegetables in the diet. Adv. Nutr. 2013, 4, 384S-392S. [CrossRef] [PubMed]

3. Eller, F.J.; Moser, J.K.; Kenar, J.A.; Taylor, S.L. Extraction and analysis of tomato seed oil. J. Am. Oil Chem. Soc. 2010, 87, 755-762. [CrossRef]

4. Sarkar, A.; Kaul, P. Evaluation of tomato processing by-products: A comparative study in a pilot scale setup. J. Food Process. Eng. 2014, 37, 299-307. [CrossRef]

5. Teh, H.E.; Yokoyama, W.H.; German, J.B.; McHugh, T.H.; Pan, Z. Hypocholesterolemic effects of expeller-pressed and solvent-extracted fruit seed oils and defatted pomegranate seed meals. J. Agric. Food Chem. 2019, 67, 6150-6159. [CrossRef]

6. Ben-Othman, S.; Joudu, I.; Bhat, R. Bioactives from agri-food wastes: Present insights and future challenges. Molecules 2020, 25, 510. [CrossRef]

7. Silva, A.C.D.; Jorge, N. Bioactive compounds of the lipid fractions of agro-industrial waste. Food Res. Int. 2014, 66, 493-500. [CrossRef]

8. Rao, S.S.; Lannutti, J.J.; Viapiano, M.S.; Sarkar, A.; Winter, J.O. Toward 3D biomimetic models to understand the behavior of glioblastoma multiforme cells. Tissue Eng. Part B Rev. 2014, 20, 314-327. [CrossRef]

9. Yoshinaga, K.; Sasaki, K.; Watanabe, H.; Nagao, K.; Inoue, N.; Shirouchi, B.; Yanagita, T.; Nagai, T.; Mizobe, H.; Kojima, K.; et al. Differential effects of triacylglycerol positional isomers containing n-3 series highly unsaturated fatty acids on lipid metabolism in C57BL/6J mice. J. Nutr. Biochem. 2015, 26, 57-63. [CrossRef]

10. Wan, J.C.; Hu, S.Y.; Ni, K.F.; Chang, G.F.; Sun, X.J.; Yu, L.L. Characterisation of fecal soap fatty acids, calcium contents, bacterial community and short-chain fatty acids in sprague dawley rats fed with different sn-2 palmitic triacylglycerols diets. PLoS ONE 2016, 11, e0164894. [CrossRef]

11. Yang, P.Y.; Zhang, H.; Wan, J.C.; Hu, J.Y.; Liu, J.C.; Wang, J.; Zhang, Y.Q.; Yu, L.L. Dietary sn-2 palmitic triacylglycerols reduced faecal lipids, calcium contents and altered lipid metabolism in Sprague-Dawley rats. Int. J. Food Sci. Nutr. 2019, 70, 474-483. [CrossRef] [PubMed]

12. Guo, Y.; Cai, Z.; Xie, Y.; Ma, A.; Zhang, H.; Rao, P.; Wang, Q. Synthesis, physicochemical properties, and health aspects of structured lipids: A review. Compr. Rev. Food Sci. Food Saf. 2020, 19, 759-800. [CrossRef]

13. Knothe, G.; Steidley, K.R. Composition of some apiaceae seed oils includes phytochemicals, and mass spectrometry of fatty acid 2-methoxyethyl esters. Eur. J. Lipid Sci. Technol. 2019, 121. [CrossRef] 
14. Barua, P.; Dutta, K.; Basumatary, S.; Deka, D.C.; Deka, D.C. Seed oils from non-conventional sources in north-east India: Potential feedstock for production of biodiesel. Nat. Prod. Res. 2014, 28, 577-580. [CrossRef] [PubMed]

15. Fokou, E.; Achu, M.B.; Kansci, G.; Ponka, R.; Fotso, M.; Tchiégang, C.; Tchouanguep, F.M. Chemical properties of some Cucurbitaceae oils from Cameroon. Pak. J. Nutr. 2009, 8, 1325-1334. [CrossRef]

16. Ngure, J.W.; Cheng, C.Y.; Yang, S.G.; Lou, Q.F.; Li, J.; Qian, C.T.; Chen, J.; Chen, J.F. Cultivar and seasonal effects on seed oil content and fatty acid composition of cucumber as a potential industrial crop. J. Am. Soc. Hortic. Sci. 2015, 140, 362-372. [CrossRef]

17. Kukeera, T.; Banadda, N.; Tumutegyereize, P.; Kiggundu, N.; Asuman, R. Extraction, quantification and characterization of oil from pumpkin seeds. Int. J. Agric. Biol. Eng. 2015, 8, 98-102.

18. Seymen, M.; Uslu, N.; Turkmen, O.; Al Juhaimi, F.; Ozcan, M.M. Chemical compositions and mineral contents of some hull-less pumpkin seed and oils. J. Am. Oil Chem. Soc. 2016, 93, 1095-1099. [CrossRef]

19. Gong, X.; Qi, N.L.; Wang, X.X.; Li, J.H.; Lin, L.J. A New Method for determination of alpha-tocopherol in tropical fruits by ultra performance convergence chromatography with diode array detector. Food Anal. Methods 2014, 7, 1572-1576. [CrossRef]

20. Zhou, Q.; Gao, B.Y.; Zhang, X.; Xu, Y.W.; Shi, H.M.; Yu, L.L. Chemical profiling of triacylglycerols and diacylglycerols in cow milk fat by ultra-performance convergence chromatography combined with a quadrupole time-of-flight mass spectrometry. Food Chem. 2014, 143, 199-204. [CrossRef]

21. Gao, B.Y.; Luo, Y.H.; Lu, W.Y.; Liu, J.; Zhang, Y.Q.; Yu, L.L. Triacylglycerol compositions of sunflower, corn and soybean oils examined with supercritical $\mathrm{CO}_{2}$ ultra-performance convergence chromatography combined with quadrupole time-of-flight mass spectrometry. Food Chem. 2017, 218, 569-574. [CrossRef] [PubMed]

22. Luo, Y.H.; Zhang, Y.Q.; Yuan, F.H.; Gao, B.Y.; Wang, Z.Y.; Yu, L.L. Triacylglycerols composition analysis of olive oils by ultra-performance convergence chromatography combined with quadrupole time-of-flight mass spectrometry. Int. J. Food Sci. Technol. 2019, 54, 871-879. [CrossRef]

23. Wang, Y.L.; Niu, Y.G.; Zhao, X.; Wang, B.Q.; Jiang, Q.Q.; Liu, J.; Sheng, Y. Fatty acid and phytochemical compositions of plantago seed oils and their functionalities. J. Am. Oil Chem. Soc. 2017, 94, 905-912. [CrossRef]

24. Marzilli, L.A.; Fay, L.B.; Dionisi, F.; Vouros, P. Structural characterization of triacylglycerols using electrospray ionization-MSn ion-trap MS. J. Am. Oil Chem. Soc. 2003, 80, 195-202. [CrossRef]

25. Gastaldi, D.; Medana, C.; Giancotti, V.; Aigotti, R.; Dal Bello, F.; Baiocchi, C. HPLC-APCI analysis of triacylglycerols in milk fat from different sources. Eur. J. Lipid Sci. Technol. 2011, 113, 197-207. [CrossRef]

26. Deineka, V.I.; Maslov, A.N.; Borzenko, O.N.; Sirotin, A.A.; Deineka, L.A. Change of triglyceride composition of cucurbitaceae and Taraxacum officinale seed oil during ripening. Chem. Nat. Compd. 2003, 39, 319-321. [CrossRef]

27. Antoniosi Filho, N.R.; Mendes, O.L.; Lancas, F.M. Computer prediction of triacylglycerol composition of vegetable oils by HRGC. Chromatographia 1995, 40, 557-562. [CrossRef]

28. Butinar, B.; Bucar-Miklavcic, M.; Valencic, V.; Raspor, P. Stereospecific analysis of triacylglycerols as a useful means to evaluate genuineness of pumpkin seed oils: Lesson from virgin olive oil analyses. J. Agric. Food Chem. 2010, 58, 5227-5234. [CrossRef]

29. Ali, M.A.; Nargis, A.; Othman, N.H.; Noor, A.F.; Sadik, G.; Hossen, J. Oxidation stability and compositional characteristics of oils from microwave roasted pumpkin seeds during thermal oxidation. Int. J. Food Prop. 2017, 20, 2569-2580. [CrossRef]

30. Jakab, A.; Heberger, K.; Forgacs, E. Comparative analysis of different plant oils by high-performance liquid chromatography-atmospheric pressure chemical ionization mass spectrometry. J. Chromatogr. A 2002, 976, 255-263. [CrossRef]

31. Nederal, S.; Skevin, D.; Kraljic, K.; Obranovic, M.; Papesa, S.; Bataljaku, A. Chemical composition and oxidative stability of roasted and cold pressed pumpkin seed oils. J. Am. Oil Chem. Soc. 2012, 89, 1763-1770. [CrossRef]

32. Rezig, L.; Chouaibi, M.; Meddeb, W.; Msaada, K.; Hamdi, S. Chemical composition and bioactive compounds of Cucurbitaceae seeds: Potential sources for new trends of plant oils. Process. Saf. Environ. 2019, 127, $73-81$. [CrossRef] 
33. Giuffrè, A.M. Variation in triacylglycerols of olive oils produced in calabria (southern italy) during olive ripening. Riv. Ital. Sostanze Grasse 2014, 91, 221-240.

34. Flori, L.; Donnini, S.; Calderone, V.; Zinnai, A.; Taglieri, I.; Venturi, F.; Testai, L. The nutraceutical value of olive oil and its bioactive constituents on the cardiovascular system focusing on main strategies to slow down its quality decay during production and storage. Nutrients 2019, 11, 1962.

35. Thao, N.; Aparicio, M.; Saleh, M.A. Accurate mass GC/LC-quadrupole time of flight mass spectrometry analysis of fatty acids and triacylglycerols of spicy fruits from the apiaceae family. Molecules 2015, 20, 21421-21432.

36. Lavillonniere, F.; Chajes, V.; Martin, J.C.; Sebedio, J.L.; Lhuillery, C.; Bougnoux, P. Dietary purified cis-9, trans-11 conjugated linoleic acid isomer has anticarcinogenic properties in chemically induced mammarytumors in rats. Nutr. Cancer 2003, 45, 190-194. [CrossRef]

37. Risérus, U.; Arner, P.; Brismar, K.; Vessby, B. Treatment with dietary trans10cis12 conjugated linoleic acid causes isomer-specific insulin resistance in obese men with the metabolic syndrome. Diabetes Care 2002, 25, 1516-1521. [CrossRef]

38. Jaudszus, A.; Mainz, J.G.; Pittag, S.; Dornaus, S.; Dopfer, C.; Roth, A.; Jahreis, G. Effects of a dietary intervention with conjugated linoleic acid on immunological and metabolic parameters in children and adolescents with allergic asthma-A placebo-controlled pilot trial. Lipids Health Dis. 2016, 15. [CrossRef]

39. Carrillo, C.; Cavia, M.d.M.; Alonso-Torre, S.R. Antitumor effect of oleic acid; mechanisms of action: A review. Nutr. Hosp. 2012, 27, 1860-1865.

40. Carrillo, C.; Cavia, M.d.M.; Alonso-Torre, S. Role of oleic acid in immune system; mechanism of action; a review. Nutr. Hosp. 2012, 27, 978-990.

41. Gillingham, L.G.; Harris-Janz, S.; Jones, P.J.H. Dietary monounsaturated fatty acids are protective against metabolic syndrome and cardiovascular disease risk factors. Lipids 2011, 46, 209-228. [CrossRef]

42. Commission Regulation (EEC) No 2568/91 on the characteristics of olive oil and oliveresidue oil and on the relevant methods of analysis. 01991R2568 - IT—04.12.2016-031. 005. Off. J. Eur. Union 1991, 248, 1-128.

43. IOC (International Olive Council). Trade Standard Applying To Olive Oils And Olive Pomace Oils; COI/T.15/NC No. 3/Rev. 13; International Olive Council: Madrid, Spain, 2019.

44. Türkmen, Ö.; Özcan, M.M.; Seymen, M.; Paksoy, M.; Uslu, N.; Fidan, S. Physico-chemical properties and fatty acid compositions of some edible pumpkin seed genotypes and oils. J. Agroaliment. Process. Technol. 2017, 23, 229-235.

(C) 2020 by the authors. Licensee MDPI, Basel, Switzerland. This article is an open access article distributed under the terms and conditions of the Creative Commons Attribution (CC BY) license (http://creativecommons.org/licenses/by/4.0/). 